\title{
Innovations
}

\section{Faculty start-up costs and library support}

\author{
By Norman D. Stevens \\ Director of University Libraries \\ University of Connecticut
}

At a time when many academic institutions, and their libraries, are facing financial challenges, it becomes difficult to maintain or develop an adequate library acquisitions budget. At the same time, neither institutions nor libraries can afford to stand still. Academic and library planning proceeds. Institutions and libraries change. At a time when traditional approaches don't produce needed resources, fresh ideas on how to obtain increased acquisitions funds need to be pursued vigorously. Apart from the usual pitch for increased private fundraising specifically targeted for library acquisitions, new approaches that link the library to the academic planning and decision-making process by building upon institutional priorities and strategies, seem to offer the greatest prospect of success.

\section{Linkages}

Although there is not yet any substantial amount of information in the literature about approaches that have brought positive results, there are a few success stories that can be cited. The 1989-90 Annual Report from the Rutgers University Libraries, for example, indicates that expenditures for library materials increased only minimally but that "subject strengthening funds, reflecting University program priorities established by the Committee on Standards and Priorities and other sources, were provided for 37 subjects in New Brunswick and 8 programs in Newark." The establishment of new academic programs or degrees, especially where approval is obtained through a formal review process, is an opportunity to seek special support for library resources that has met with success in some institutions. Tying the need for additional library resources to academic priorities or program development makes the appeal for funds more real and immediate and less self-centered.

\section{Faculty start-up costs}

One of the most serious competitive challenges now confronting many academic institutions is the recruitment of new faculty. While the availability of qualified candidates and the level of competition varies from discipline to discipline and institution, the evidence is that most academic institutions regard the ability to hire the best possible new faculty, as well as to attract minorities and women, as one of the most critical issues before them. Institutions may be limited in what they can pay but they have become increasingly innovative in examining alternative benefits that they can offer in their efforts to hire highly qualified and sought-after faculty.

\section{As the university seeks to attract new faculty in an increasingly competitive market, the ability to offer those faculty start-up funding in the form of a special allocation for library materials...can be an attractive incentive.}

A recent memo from the provost and academic vice president of the University of Connecticut, for example, cogently makes an argument for the state to provide the University with substantial capital equipment funds for new faculty start-up costs.

"The key element needed to insure a high-quality teaching, research, and public service university is the continuing ability to hire and retain quality 
faculty. The marketplace for hiring new faculty, particularly in the scientific fields, has become extremely competitive within the last five years and is predicted to become even tighter in the years ahead. This competitiveness is an outcome of three basic factors. First, as with the overall workforce in general, much of the current faculty cohort is aging together and will retire duringthis decade...Second, sufficient replacements are not being trained. In numerous fields, the demand for outstanding applicants far outstrips the supply. Third, outstanding faculty often are able to leverage a dollar of investment in start-up into four or five dollars in grant awards. What has emerged is a very strong and highly competitive sellers market in many academic fields. The university must bid competitively against other universities for the most qualified candidates. And the provision of adequate start-up support has often become the single most important factor in successfully recruiting new faculty."

Typically, such start-up costs are highest and most visible in the sciences. In those disciplines faculty need specific equipment and laboratory

\section{As Arlo Guthrie once suggested, if 3 libraries are able to do so, they may think it is a move- ment; if 50 libraries do so, they may think it is an organization.}

facilities, which a university probably does not possess because of obsolescence and changing interests. The University of Connecticut memo suggests that those start-up costs may range from $\$ 250,000$ to $\$ 1,000,000$ depending on the discipline and the stature or desirability of the candidate.

In responding to that memo, I sought to make the case, which has been accepted in principle, that start-up costs also ought to include the new library collections needed by faculty in all disciplines but especially in the humanities and the social sciences. I suggested that, "the University Libraries have traditionally been in a position to build strong research collections primarily by working closely with individual faculty members. As a result the quality of those collections is uneven and tends to reflect individual faculty interests. That, along with changing patterns of interest in almost every academic field, means that when new faculty join the University there is often a need for the university Libraries to acquire additional, specialized research material to support their primary research interest.
That is true of faculty in all disciplines but is especially true of those in the social sciences and humanities who rely on the University Libraries as the chief support for their research. As the university seeks to attract new faculty in an increasingly competitive market, the ability to offer those faculty start-up funding in the form of special allocation for library materials, to be expended by the faculty member in consultation with appropriate staff in the Libraries, can be an attractive incentive."

Fortunately this turns out to be a not entirely new idea although my efforts to identify other institutions offering such incentives have turned up only a few examples to date. At the university of Iowa, for example, the strategic plan of the university and that of the University Libraries incorporates this idea. There is now in place at the University of Iowa a formal process whereby academic department heads, working closely with the administration of the University Libraries, identify the need for library start-up costs as part of the recruitment process. If a formal library request is then made to the vice president for academic affairs, the dean of liberal arts is informed so that he may participate in the decision as to whether or not such support is warranted from his perspective in terms of recruitment to fill positions. The recruitment of two new faculty members in Asian religious studies brought $\$ 50,000$ in special funds to the University Libraries to establish appropriate Buddhist collections with the promise of an additional $\$ 50,000$ over a period of several years. The University Libraries also received $\$ 25,000$ to support new faculty and an expanded program in Soviet and East European Studies as the result of a proposal developed by those faculty. The amounts provided at the University of Iowa have been modest, especially in comparison to the costs of equipment and laboratories for scientists. Library start-up costs in general may be modest, but that special support represents a recognition of the principle and a starting point that we can perhaps all build upon.

At the University of Connecticut, similar efforts have been initiated with the chairman of the History Department, which is now seeking to fill an endowed chair in modem Italian history, and the director of the African-American Studies Institute, which is assisting with the recruitment of six faculty members in several disciplines, to obtain such added support. They are supportive of the idea and will be discussing it with the candidates they wish to hire. There are a few indications that similar efforts and or discussions are underway at other institutions.

\section{Working together}

The real virtues of this approach to obtaining additional library support directly from the institution, in a time of financial constraint, are that, on the 


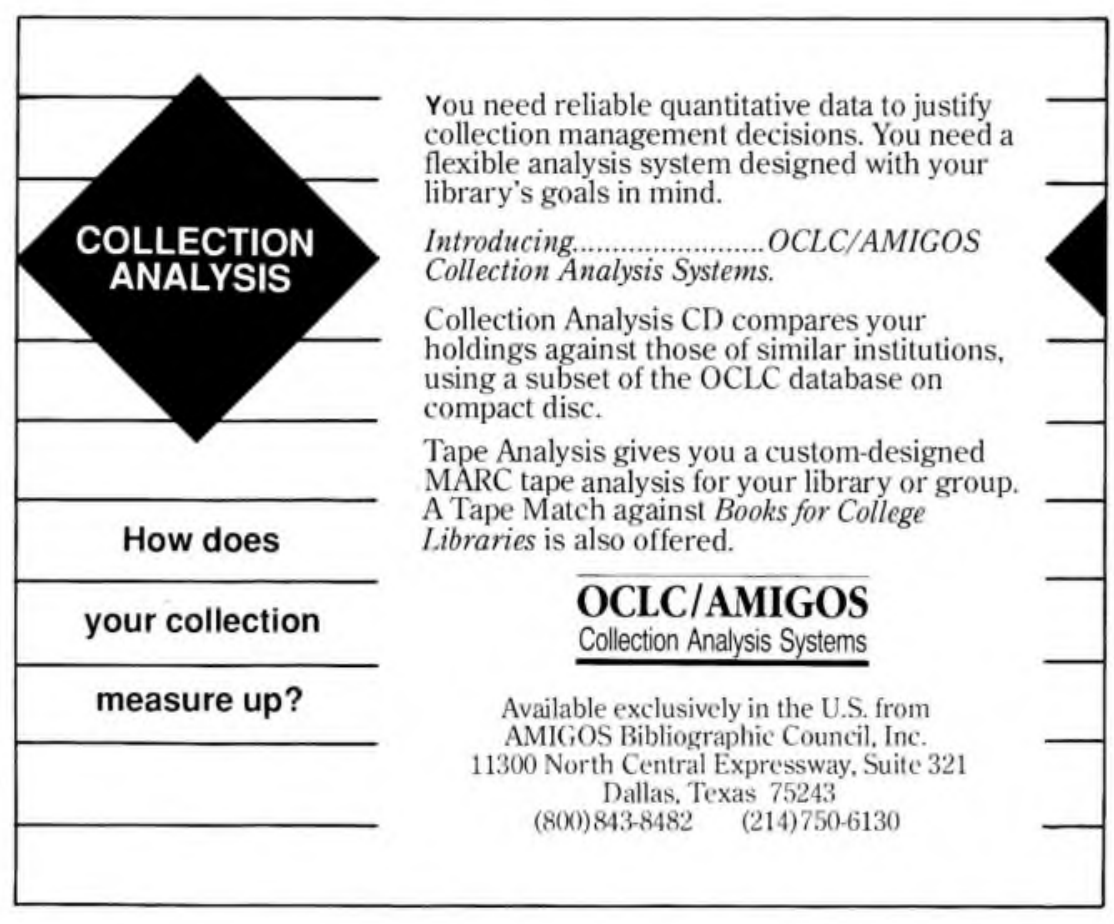

one hand, it builds upon a recognized institutional priority and strategy, and that, on the other hand, the case is being made for the library by the institutional personnel seeking to hire a strong candidate and/or by a candidate whom the institution wishes to attract. That is a fresh idea that seems to offer a formula for success.

A cynic might suggest that the scientific community has banded together to promote the need for academic institutions to build and equip new laboratory facilities to attract promising faculty as a matter of collective self-interest. For whatever reason, the provision of such facilities is rapidly becoming an essential element of the recruitment process. If the academic library community can band together in promoting the need for academic institutions to build new library collections for the same reason, perhaps we can have the same success. The more examples we can identify of academic institutions that do include information resource start-up costs as part of a larger organized program of support to attract new faculty, the more likely we are to establish that as a desirable and established component of the faculty recruitment process. As Arlo Guthrie once suggested, if three libraries are able to do so, they may think it is a movement; and if 50 libraries do so, they may think it is an organization. We need a movement if not eventually an organization. For that reason, information about such discussions and efforts, and especially about successful programs at other academic institutions, is solicited.

\section{Letters}

The following letter to Eileen Cooke, ALA Washington Office, was forwarded to the editor:

Dear Eileen: I just wanted to confirm in writing my appreciation of the efforts of your office in tracking federal information activities and to commend in particular Carol Henderson's regular reports in C\&RL News. Keep up the good work! $-M$. Jacob, M.E.L. Jacob Associates, Columbus, Ohio

\section{To the Editor:}

I'd like to hear from institutions that provide nocost database searching to their primary clientele (students, faculty, etc.). I would like information on: the total cost of their "free" database searching; their total budget for the library; the clientele that gets this service; policies that delineate inclusion or exclusion for such a service; who must pay for database searching and why; their total expenditures for books/monographs; their total expenditures for serials; and any other information. Data for the latest fiscal year is preferred. Please write to: Harvey Varnet, Director, University Library, Governors State University, University Park, IL60430.Harvey Varnet, Governors State University 